\title{
Home-Bias Investment Measure: Evidence from a Repeated Experiment in Taiwan
}

\author{
Wei-Lung Huang ${ }^{1 *}$ and Yan-Kai Fu² \\ ${ }^{1}$ Assistant Professor, Department of Finance, China University of Science and Technology, Taiwan \\ ${ }^{2}$ Assistant Professor, Department of Business Administration, China University of Science and Technology, Taiwan
}

\begin{abstract}
This study uses repeated experiment to explore the possible reasons of home-bias investment. The results indicated that the reasons for home-bias investment are information asymmetry or familiarity, resulting in over-investment in Taiwanese investment vehicles. The level of home-bias investment changed with the level of information asymmetry changes. A significant difference in home-bias investment was observed for different levels of education, investment experience, age, annual income and annual investment. Moreover, the difference in investment ratio did not change based on different levels of information asymmetry.
\end{abstract}

Keywords: Home-bias investment; Investment portfolio; Experimental questionnaire

\section{Introduction}

Today, cross-border investment barriers have been substantially reduced. To pursue the maximum rate of return of investment portfolios, investors actively invest in foreign financial markets. For example, as of the end of February 2010, Taiwanese investors held 1,004 accounts of offshore funds (the amount was NT \$ 2.07 trillion). Various studies showed that the main reason for investors to hold foreign investment vehicles is the increase of the rate of return or risk reduction. For example, Karolyi and Stulz [1] reviewed the literature available on the international factors influencing the demand and prices of financial assets. They found that when cross-border investment barriers do not exist and the investor's investment decisions are affected by the mean and variance of the return of investment (ROI) in invest vehicles of various countries, an investor's portfolio should include investment vehicles in various countries.

At present, the investment portfolio of most investors is still primarily composed of Taiwanese assets (called home-bias investment in this study) and does not differ across countries, levels of knowledge and professional levels. Howell and Cozzini [2] observed that the proportion of domestic securities held by domestic investors in December 1986 was $92 \%$ in the United States, $95.7 \%$ in Japan, $92 \%$ in UK, 79\% in Germany and 89.4\% in France. Cooper and Kaplanis [3], Kang and Stulz [4] and Tesar and Werner [5] proved that investors in various countries all have home-bias investment. In addition, Karolyi and Stulz [1] observed that home-bias investment caused gradually reduced profit in cross-border investments, and Chan et al. [6] observed that home-bias investment also exists in mutual funds (investment professionals).

Based on the summary of various studies, home-bias investment occurred because of information asymmetries or familiarity; that is, over-investment into domestic investment vehicles occurred because information on domestic securities is easier to obtain and because domestic investors are more familiar with the information. French and Poterba [7] used the model of investor preferences to prove that the expected ROI of domestic assets is much higher than that of international ones and that the reason for home-bias investment is the investor's investment decision rather than institutional constraints. Using the framework of international expect at ions with background noise, Gehrig [8] and Brennan and Cao [9] observed that when investors have more accurate information on domestic investment vehicles, home-bias investment ma y occur. Shiller et al. [10], Kilka and Weber [11], Ackert et al. [12] and Strong and Xu [13] proved that familiarity will affect the investor's level of optimism and trust and then generate the expectation bias of risk and reward. Shiller et al. [10] noted that investors expect better performance for domestic securities than for foreign securities. Huberman [14] showed that investors are more prone to have a sense of trust with familiar things; thus, investors prefer to invest in more familiar companies. Ackert et al. [12] used an experimental questionnaire and determined that investors do not prefer domestic securities if the production is not home-based. For example, when the subjects were informed of the name of the securities, the y could associate the securities with the parent company. If the company's production base was not in the home country, the subject $s$ would select other countries for investment.

Investors are unable to distinguish between the level of information asymmetry or familiarity for domestic and foreign investment vehicles; moreover, the existing studies have not yet clarified whether homebias investment varies based on different degrees of information asymmetries or familiarity. Therefore, the first objective of this study was to use an experimental questionnaire to control for the level of information asymmetry and to explore the impact of the level of information asymmetry or familiarity with domestic and foreign investment vehicles on the investor's home-bias investment. The purpose of the experimental questionnaire used in this study was to investigate the investor's allocation status of funds to domestic and foreign assets when presented with different information. Moreover, in

*Corresponding author: Wei-Lung Huang, Assistant Professor, Department of Finance, China University of Science and Technology, No.245, Sec.3 Academia Rd, Nangang Dist, Taipei City 11581, Taiwan, Tel: (H)02-87320876; Fax: (02) 27864501; E-mail: hippoobee@yahoo.com.tw

Received December 12, 2013; Accepted January 28, 2014; Published January 31, 2014

Citation: Huang WL, Fu YK (2014) Home-Bias Investment Measure: Evidence from a Repeated Experiment in Taiwan. J Bus Fin Aff 3:117 doi:10.4172/2167 0234.1000117

Copyright: (c) 2014 Huang WL. This is an open-access article distributed under the terms of the Creative Commons Attribution License, which permits unrestricted use, distribution, and reproduction in any medium, provided the original author and source are credited. 
the experimental questionnaire, in addition to controlling for the level of information asymmetry of the subjects, interfering variables such as the transaction costs and the risk level of the subjects' portfolio could also be controlled.

The experimental questionnaire used in this study controls for the level of information asymmetry; that is, the level of information received by various groups of subject $s$ was different. Existing studies have not yet explored whether the domestic bias of investors changes depending on the amount of information at the starting point of investment (i.e., frame effect) or the amount of information (i.e., the level of information asymmetry). Therefore, the second objective of this stud $y$ was to use the repetitive experimental questionnaire to change the level of information asymmetry and then to explore the framing effect and the impact of the changes in the level of information asymmetry on the home-bias investment. Earl and Morgan [15] divided information processing into three stages: acceptance, perception and action. In the perception stage, empirical experience is prone to cause subjective judgment bias (i.e., (the framing effect). Tversky and Kahneman [16] defined the framing effect refers as the phenomenon in which precisely the same decision-making situation will lead to different decision-making behaviors based on differences in the presentation of information. Levin et al. [17] explored three types of framing effects: risk selection framework, attribute framework and target framework. The risk selection framework explains how framing affects the willingness of consumers to take risks [16] the attribute framework explains how framing affects the consumer's assessment of the subject matter or event [18], and the target framework explains how framing affects the convincibility of communications [19].

Because the level of information asymmetry of domestic and foreign investment vehicles is subject to the investor's personal variables (such as gender, age, education level and occupation), home-bias investment may be affected by the investor's persona 1 variables and by familiarity with domestic and foreign investment vehicles. Therefore, the third objective of this study was to use an independent sample $\mathrm{T}$ test and correlation analysis to explore whether home-bias investment would change based on an investor's personal variables and familiarity with domestic and foreign investment vehicles and, moreover, whether the difference in home-bias investment changed with an adjustment in the level of information asymmetry. In addition, regression equations were used to explore the effect of the investor's personal variables and familiarity with domestic and foreign investment vehicles on the home-bias investment.

This paper is divided into four parts: an introduction, a description of the stud y design, an analysis of the results and conclusions and suggestions.

\section{Study Design}

To control for the subjects' level of information asymmetry and considering that the performance and basic information on the investment vehicles affects investment decisions, this study divided the information provided concerning the investment vehicles into four categories: no information, performance information, basic information and all information (i.e., both performance and basic information). The performance information included the ROI of investment vehicles, standard deviation, $\beta$ Sharpe index and Treynor index. The basic information included the scale of the investment vehicles, management fees, custodial fees, service fees and investment targets ${ }^{1}$.

To control for the framing effect and the type of subjects, this study divided the subjects into four groups, and four experiments were conducted in each group. The type of information received during the first experiment was different in each group, and the type of information received in each experiment was also different (Table 1). Each experiment lasted for 30 minutes. The subjects rested for one hour before the next experiment. The entire duration of the experiments was five hours ${ }^{2}$.

The subjects answered six questionnaires. During the first experiment, the subjects answered three questionnaires related to personal data, the investment environment in various countries and their portfolio. During the second, third and fourth experiments, the subjects answered one questionnaire per experiment. The questionnaire on personal data was used to explore the personal factors that may influence home-bias investment. The questions included information on gender, age, educational level, occupation, annual income, the number of investment courses previously taken (number of investment courses), amount of annual investment and whether the investor had previously invested in more than two types of investment vehicles (investment experience). The purpose of surveying the number of investment courses previously taken was to understand whether the subjects understood the concepts of the pursuit of ROI and risk diversification. The purpose of surveying whether the subjects had previous experience investing in more than two types of investment vehicles was to understand whether the subjects understood the concept of an investment portfolio.

${ }^{1}$ The performance information of the investment vehicles provided in this study was the ROI (old Taiwanese currency) for 1,3 and 6 months and 1, 2 and 3 years 3-year standard deviation (NT), 3- $\beta$ value (NT), 3-year Sharpe index (NT) and 3 -year Treynor index (NT). The base point of the information was December 31 2009. ROI provided the subjects with the profits and future trend of investment vehicles. The standard deviation, $\beta$, Sharpe index and Treynor index provided the subject with the risk of the investment vehicles. Basic information was provided so that the investors could understand the relevant fees for various investment vehicles and select investment vehicles believed to have potential for portfolio allocation, according to the scales and investment targets.

${ }^{2}$ To explore the effect of the framing effect and different levels of information on home-bias investment, this study used one hour as the interval between experiments because after one hour, the subjects may still have some memory of the information in the previous experiment. The forgetting curve in Ebbinghaus (1885) showed that the average memory retention rate was roughly $58 \%$ after $20 \mathrm{~min}$, $44 \%$ after one hour and $35 \%$ after eight hours.

\begin{tabular}{|l|l|l|l|}
\hline & 1th group & 2nd group & 3rd group \\
\hline 1th & no information & performance information & basic informatio $\mathrm{n}$ \\
\hline 2nd & performance information & basic information & all information \\
\hline 3rd & basic information & all information & all information \\
\hline 4th & all information & no information & performance informatio $n$ \\
\hline
\end{tabular}

Table 1: The order of various types of information received by the subjects in each group 
The questionnaire on the investment environment in various countries was used to explore the subjects' familiarity with the investment environment in various countries. The questions included topics such as national financial markets, economic conditions, market risk, credit risk, liquidity risk, operational risk, regulator y risk and whether the subjects lived in the country before. In this study, the level of familiarity for each question was scored on a scale of 1-10. The average score of each question regarding Taiwan was defined as the level of familiarity with the Taiwanese investment vehicles, and the average score for each question related to other countries was defined as the level of familiarity with foreign investment vehicles. In this study, the countries included on this questionnaire were those that offered investment vehicles on the portfolio questionnaire, such as Taiwan, mainland China, the United States, India, Japan, South Korea, Thailand, Australia, Singapore, Hong Kong, UK and Switzerland. The questions on topics such as national financial markets, economic conditions and whether the subjects lived in the country before were designed to understand the subjects' level of understanding of the ROI of investment vehicles in various countries. Questions concerning market risk, credit risk, liquidity risk, operational risk and regulator y risk were designed to understand the subjects' level of understanding of the risk of the investment vehicles in various countries.

The portfolio questionnaire used in each experiment asked the subjects to full $y$ allocate $\$ 1,000,000$ into the portfolio tab le (the amount of investment could be zero, but it could not be negative), with reference to various types of information. Then, the answers were used to understand whether there was home-bias investment in the subject s' investment behavior and whether the extent of home-bias investment was affected by the level of information asymmetry and familiarity, the framing effect and the type of information change.

The fifteen domestic and foreign investment vehicles included in the portfolio questionnaire were three exchange-traded funds (ETFs), eleven publicly traded mutual funds and one time deposit. The Taiwanese investment vehicles included were one Taiwanese ETF (domestic ETF), one Taiwanese publicly traded mutual fund (domestic mutual fund) and the Taiwanese post office time deposit (domestic time deposit). The foreign investment vehicles included were two offshore ETFs (foreign ETFs) and ten offshore publicly traded mutual funds (foreign mutual funds). Because, among the foreign investment vehicles, investors were more likely to select ETFs and publicly traded mutual funds, the time deposit was the most common risk-free asset and home-bias investment was the focus of this study, the investment vehicles included on the portfolio questionnaire were divided into five types of investment vehicles: the Taiwanese ETF, Taiwanese mutual funds, foreign ETFs, foreign mutual funds and the Taiwanese time deposit $^{3}$.

To explore whether home-bias investment changed with different investment portfolios, this study divided the portfolio questionnaire into ETF and time deposit (Type A), publicly traded mutual funds and time deposit (Type B), and ETF, publicly traded mutual funds and time deposit (Type C). The different portfolio groups had a different number of investment vehicles that investors knew or could purchase, and the number of investment vehicles investors knew represented the level of information asymmetry. The number of investment vehicles investors could purchase represented the level of governmental control of the investment vehicles. For example, Taiwan's Financial Management Committee audited investment vehicles that were listed in the Taiwanese market, in accordance with political factors or the financial market and system.
Because the investment amount in the experimental questionnaire could require an alteration of our hypothesis, the reference value of the investment amount was small. Thus, this study focused on the investment ratio and used SPSS17.0 for the descriptive statistical analysis of the questionnaire data and hypothesis testing (such as correlation analysis, paired sample $\mathrm{T}$ tests, analysis of variance (ANOVA), regression analysis and single factor ANOVA analysis). For example, based on the overall data, the grouping of the type of information and the portfolio, the descriptive statistics of various investment ratios were calculated and compared. This study then explored whether there was home-bias investment in Taiwanese investors' investment behavior and whether Taiwanese investors' home-bias investment varied based on type of information or the grouping of the portfolio.

In addition, this study used Kolmogorov-Smirnova and ShapiroWilk normality tests to test the investment ratio of the subjects of different gender, educational level, occupation and investment experience and the experimental group. If the criterion of a normal distribution was met, then an independent sample $\mathrm{T}$ test was performed to compare the averages. Otherwise, the Kruskal-Wallis $\mathrm{H}$ test of K nonparametric independent samples and the Mann-Whitney $\mathrm{U}$ test of two independent samples were used to explore the following: (1) whether an investor's investment ratio would vary depending on gender, educational level, occupation and investment experience and whether the level of the investment ratio changed with the adjustment of the level of information asymmetry; (2) whether an investor's home-bias investment would vary based on differences in the type of information initially provided (framing effect).

Moreover, this stud y analyzed the correlation between the subjects' personal variables (age, annual income, the number of investment courses previously taken, annual investment amount, familiarity with Taiwanese investment vehicles and familiarity with foreign investment vehicles) and the investment ratio. This study then explored whether there was significant correlation between a Taiwanese investor's investment ratio and these personal variables and whether the correlation in the investment ratio varied significantly based on the level of information asymmetry.

Furthermore, this stud y used paired sample $\mathrm{T}$ tests to determine investment ratios when the same subject received different types of information (no information, performance, basic information, all information) or different portfolios (Type A, B, C) and then to explore whether a Taiwanese investor's home-bias investment changed with the adjustment in the type of information or portfolio (i.e., the level of information asymmetry).

Finally, this study used regression equations to verify the extent of the effect of investor's personal variables and familiarity

${ }^{3}$ As of the end of 2009, 14 ETFs (11 domestic component securities ETFs and 1 foreign component securities ETF) could be publicly traded in Taiwan. The ETFs selected by the portfolio questionnaire were the oldest and largest "Polaris Taiwan Top 50 securities investment trust funds" and the offshore ETFs, "Hang Seng HShare ETF" and "Hang Seng ETF". The selection criteria for publicly traded mutua funds were: general equity funds invested in only one country, the funds from the top 11 countries with regard to the amount of holdings by Taiwanese investors and the funds with the highest 3-year ROI. Finally, the publicly traded mutual funds selected for the portfolio questionnaire were the Yongfeng SinoPac Securities Investment Trust Fund in Taiwan, Threadneedle (Lux) in the United States - American Equity Fund (USD), AIG Global Funds in India - AIG India Equity Fund Y, Fidelity Investment Fund in Japan - Japanese Potential Fund ( $Y$ share of cumulative shares - yen), JF South Korea Fund in South Korea, JF Thailand Fund in Thailand, Lion Capital Australia Fund in Australia (USD), Singapore UBS (Lux) Equity Fund in Singapore, UK Prudential Fund Company in Hong Kong - Prudential Hong Kong Fund, UK Prudential Group M \& G New Opportunity Fund and Switzerland Falcon Swiss Equity Fund in Switzerland. 
with domestic and foreign investment vehicles on the homebias investment. The regression equation used was as follows $Y_{i}=\alpha_{0, i}+\beta_{1, i} X_{1, i}+\beta_{2, i} X_{2, i}+\beta_{3, i} X_{3, i}+\beta_{4, i} X_{4, i}+\beta_{5, i} X_{5, i}$ $+\beta_{6, i} X_{6, i}+\beta_{7, i} X_{7, i}+\beta_{8, i} X_{8, i}+\beta_{9, i} X_{9, i}+\beta_{10, i} X_{10, i}+\varepsilon_{i}$

where $\mathrm{Yi}$ is the investment ratio of the domestic investment vehicles, $\mathrm{X}_{1, \mathrm{i}}$ is gender, $\mathrm{X}_{2, \mathrm{i}}$ is age, $\mathrm{X}_{3, \mathrm{i}}$ is the education level, $\mathrm{X}_{4, \mathrm{i}}$ is occupation, $\mathrm{X}_{5, \mathrm{i}}$ is annual income, $X_{6, \mathrm{i}}$ is the number of investment courses previously taken, $\mathrm{X}_{7, \mathrm{i}}$ is the annual investment amount, $\mathrm{X}_{8, \mathrm{i}}$ is the investment experience, $\mathrm{X}_{9, \mathrm{i}}$ is the familiarity with domestic investment vehicles and $X_{10, i}$ is the familiarity with foreign investment vehicles. $i=1-4, i=1$ is domestic ETF, portfolio A; i=2 is domestic mutual funds, portfolio $\mathrm{B} ; \mathrm{i}=3$ is domestic ETF, portfolio $\mathrm{C}$; and $\mathrm{i}=4$ is domestic mutual funds, portfolio $\mathrm{C}^{4}$.

\section{Statistical Analysis}

This study divided the subjects into four groups. 52, 36, 42 and 35 valid questionnaires were collected from Group 1,2,3 and 4, respectively. There were 53 male and 112 female subject s; 102 subjects were younger than 25 years of age, and 63 were older than 26 years of age; 139 had received a college education, and 26 had a graduate degree; 89 were students, and 76 were employed; 105 earned less than NT \$300,000/ year, and 60 earned more than NT \$300,001/year; 87 had taken less than 10 investment courses, and 78 had taken more than 11 investment courses; 101 invested less than NT \$25,000/year, and 64 invested more than NT \$25,001/year; and 75 had previously invested into more than two types of investment vehicles, and 95 had never invested into more than two types of investment vehicles. The distribution of each group was similar to that of the overall d istribution ${ }^{5}$.

Concerning the level of familiarity (mean of the sum) with the investment environment in various countries, the subjects were most familiar with Taiwan, followed by mainland China, the United States, Japan and Hong Kong. There was no significant difference for the remaining countries. The distribution of each question and each group was similar to that of the overall distribution.

Concerning the descriptive statistical results of the portfolio questionnaire, when the fifteen domestic and foreign investment vehicles were analyzed, there was home-bias investment in the investment behavior of Taiwanese investors. Regardless of the overall data, for grouping of the type of information or of the portfolio, the subjects' investment ratios (mean) were the highest for Taiwanese ETF, Taiwanese mutual funds and Taiwanese time deposit. The variance of the subjects' investment ratio demonstrated similar results.

According to the descriptive statistical results of the portfolio questionnaire, investor home-bias investment varied with the grouping of the type of information or of the portfolio. This study assumed that the number of investment vehicles could be viewed as the level of information asymmetry for investors; therefore, the level of information asymmetry was one of the reasons for home-bias investment, and the reduction of the level of information asymmetry (performance, basic information or the disclosure of investment vehicles) could reduce the investor's home-bias investment. For the groups that received different types of information, the investment ratio of Taiwanese ETF or Taiwanese mutual funds (mean) was decreased in the sequence of no information, basic information, performance and all the information. The effect of performance was far larger than basic information on home-bias investment. For the groups of different portfolios, the investment ratio of Taiwanese ETF or Taiwanese mutual funds (mean) was the highest for Type A, followed by Type B and Type C.
According to the descriptive statistical results of the portfolio questionnaire, the investment behavior of Taiwanese investors depended on their familiarity with the investment environment in various countries. Therefore, the level of familiarity was one of the reasons for home-bias investment. For example, the investment ratio (mean) of ETFs in mainland China, mutual funds in the United States, mutual funds in Japan, ETFs in Hong Kong and mutual funds in Hong Kong varied with the type of information or the grouping of portfolio; in the grouping method, the ratio was the second highest, and the investment ratios (means) of the aforementioned investment vehicles in the remaining countries were all small.

When the descriptive statistical results of the portfolio questionnaire were analyzed in terms of Taiwanese ETFs, Taiwanese mutual funds, foreign ETFs, foreign mutual funds and the Taiwanese time deposit, the level of Taiwanese investors' home-bias investment was smaller than in previous studies, which was caused by the high level of internationalization of Taiwanese financial market and the universality of financial knowledge among the Taiwanese population. Because the investment ratios of various foreign investment vehicles were quite small and the focus of this study was on home-bias investment, this study hypothesized that the investment ratio of foreign ETFs and foreign mutual funds was the sum of that of the two offshore ETFs and the ten offshore mutual funds. The subjects' investment ratios (mean) were mostly the highest in foreign ETFs or foreign mutual funds (except one group), and the order of the variance of the subjects' investment ratios indicated similar results.

The analysis of variance results of the subjects' investment ratio according to gender, educational level, occupation and investment experience is presented in Table 2. There was no significant difference in most of the investment ratios of Taiwanese investors regarding gender, educational level, occupation and investment experience. However, occupation had the largest effect, and the difference in the investment ratios did not vary with the level of information asymmetry. The results of the normality test verified that a normal distribution of the investment ratios was present when the subjects of different gender, educational level, occupation and investment experience were grouped according to investment portfolio, the type of information and investment vehicles. Moreover, this study used independent sample T tests to explore whether there was a difference in the investment ratios of Taiwanese investors based on gender, educational level, occupation and investment experience. Only 24 of the $176 \mathrm{~T}$ tests with an equal mean had significant results, of which 2 results indicated significance in gender, 7 in educational level, 10 in occupation and 5 in investment experience ${ }^{6}$.

The results of Table 2 indicate that there was a significant difference in the investment ratio of Taiwanese investment vehicles based on the difference in educational level or investment experience. Moreover,

${ }^{4}$ The coding of each question on the questionnaire of personal data was: male $=0$, female $=1 ;=$ age; college education $=0$, graduate degree $=1 ;$ student $=0$, em ployed $=1 ;=$ annual income $=$ the number of investment courses previously taken $=$ the annual investment amount; invested into more than two kinds of investment vehicles before $=0$, never invested into more than two kinds of investment vehicles $=1$; = familiarity with Taiwanese investment vehicles; = familiarity with foreign investment vehicles.

${ }^{5}$ Due to the complexity of the questionnaire results, this study only introduced the most important and significant results. If further details are needed, please contact the author.

${ }^{6}$ This study calculated the results of $176 \mathrm{~T}$ tests with an equal mean, based on the four questions concerning personal data (gender, educational level, occupation and investment experience), the four types of information and eleven investment vehicles (three types of portfolio) 
Citation: Huang WL, Fu YK (2014) Home-Bias Investment Measure: Evidence from a Repeated Experiment in Taiwan. J Bus Fin Aff 3:117 doi:10.4172/2167-0234.1000117

Page 5 of 9

\begin{tabular}{|c|c|c|c|c|c|c|}
\hline & investment portfolio & Types of Information & investment vehicles & Levene Test $(F)$ & T test & Average Difference \\
\hline \multirow{2}{*}{ gender } & Type A & basic information & foreign ETFs & 0.420 & $-0.049^{*}$ & -0.002 \\
\hline & Type C & basic information & foreign mutual funds & 0.132 & $-0.033^{*}$ & -0.001 \\
\hline \multirow{7}{*}{ education level } & Type A & performance information & Taiwanese ETF & 0.004 & $0.059^{*}$ & 0.002 \\
\hline & \multirow{2}{*}{ Type B } & no information & $\begin{array}{l}\text { Taiwanese mutual } \\
\text { funds }\end{array}$ & 0.802 & $-2.527^{*}$ & -0.080 \\
\hline & & all information & $\begin{array}{l}\text { Taiwanese mutual } \\
\text { funds }\end{array}$ & 0.826 & $-0.041^{*}$ & -0.001 \\
\hline & \multirow{4}{*}{ Type C } & \multirow{2}{*}{ performance information } & $\begin{array}{l}\text { Taiwanese mutual } \\
\text { funds }\end{array}$ & 1.936 & $-2.899^{* *}$ & -0.083 \\
\hline & & & $\begin{array}{l}\text { Taiwanese time } \\
\text { deposit }\end{array}$ & 2.308 & $-0.046^{*}$ & -0.002 \\
\hline & & \multirow{2}{*}{ basic information } & $\begin{array}{l}\text { Taiwanese mutual } \\
\text { funds }\end{array}$ & 4.590 & $-3.256^{* \star *}$ & -0.075 \\
\hline & & & $\begin{array}{l}\text { Taiwanese time } \\
\text { deposit }\end{array}$ & 0.979 & $-0.039^{*}$ & -0.002 \\
\hline \multirow{10}{*}{ occupation } & \multirow{2}{*}{ Type A } & no information & Taiwanese ETF & 0.653 & $-0.035^{\star}$ & -0.001 \\
\hline & & performance information & foreign ETFs & 0.047 & $0.041^{*}$ & 0.002 \\
\hline & \multirow{2}{*}{ Type B } & no information & foreign mutual funds & 1.085 & $2.469^{*}$ & 0.094 \\
\hline & & basic information & foreign mutual funds & 0.622 & $2.011^{*}$ & 0.073 \\
\hline & \multirow{6}{*}{ Type C } & \multirow{2}{*}{ no information } & Taiwanese ETF & 3.143 & $-2.467^{*}$ & -0.050 \\
\hline & & & foreign mutual funds & 2.534 & $3.095^{\star \star}$ & 0.112 \\
\hline & & performance information & foreign mutual funds & 0.132 & $2.314^{*}$ & 0.081 \\
\hline & & \multirow{3}{*}{ all information } & Taiwanese ETF & 0.044 & $-2.458^{*}$ & -0.053 \\
\hline & & & foreign ETFs & 7.081 & $-2.222^{*}$ & -0.051 \\
\hline & & & foreign mutual funds & 0.227 & $2.425^{*}$ & 0.088 \\
\hline \multirow{5}{*}{ investment experience } & \multirow{2}{*}{ Type B } & performance information & $\begin{array}{l}\text { Taiwanese mutual } \\
\text { funds }\end{array}$ & 5.018 & $2.034^{*}$ & 0.050 \\
\hline & & basic information & $\begin{array}{l}\text { Taiwanese time } \\
\text { deposit }\end{array}$ & 0.006 & $-0.022^{*}$ & -0.001 \\
\hline & \multirow{3}{*}{ Type C } & performance information & Taiwanese ETF & 0.373 & $2.677^{\star *}$ & 0.052 \\
\hline & & basic information & $\begin{array}{l}\text { Taiwanese time } \\
\text { deposit }\end{array}$ & 0.742 & $-0.029^{*}$ & -0.001 \\
\hline & & all information & $\begin{array}{l}\text { Taiwanese time } \\
\text { deposit }\end{array}$ & 0.149 & $-0.002^{* *}$ & $-4.500 \times 10^{5}$ \\
\hline
\end{tabular}

Note ${ }^{*} p<.05,{ }^{* *} p<.01,{ }^{* * *} p<.000$

Table 2: The analysis of variance of the subjects' investment ratio due to gender, educational level, occupation and investment experience.

the higher the educational level, the lower the investment ratio of the Taiwanese investment vehicles (roughly $8 \%$ ). The investment ratio of the Taiwanese time deposit often decreased slightly with more investment experience. Furthermore, the investment ratio of the foreign mutual funds increased dramatically (roughly 8-11\%) based on the occupation of Taiwanese investors.

The results of the correlation analysis of the subjects' personal variables (age, annual income, the number of investment courses previously taken and annual investment amount) and the investment ratios are provided in Table 3 . There was no significant correlation between the majority of the investment ratios and age, annual income, the number of investment courses previously taken and annual investment amount, and the significance of a small number of investment ratios varied with the level of information asymmetry. Only 15 of the 176 correlation analyses had significant results, of which, 5 results were significant in age, 7 in annual income, 0 in the number of investment courses previously taken and 3 in the annual investment amount. Moreover, 14 of the 15 significant results were from the groups that received no information or basic information.

The results in Table 3 indicate that for Taiwanese investment vehicles, there was a significant positive correlation between the investment ratio of Taiwanese investors and age, annual income and annual investment amount. For the foreign funds, there was a significant negative correlation between the investment ratio of
Taiwanese investors and age, annual income and annual investment amount. Therefore, the older the subject $s$, the higher the annual income, and the larger the amount of annual investment, it means that the higher the level of the Taiwanese investor's home-bias investment.

The results of the correlation analysis of the subjects' personal variables (familiarity with Taiwanese and foreign investment vehicles) and investment ratios are provided in Table 4 . There was significant correlation between the investment ratio of Taiwanese investment vehicles and familiarity with Taiwanese and foreign investment vehicles, and there was no significant correlation between the investment ratio of foreign investment vehicles and familiarity with Taiwanese and foreign investment vehicles. In addition, the significance of the investment ratio did not vary with the level of information asymmetry. Twenty of the 56 correlation analyses of Taiwanese investment vehicles had significant results, and 3 of the 32 correlation analyses of foreign investment vehicles had significant results. Moreover, 10 results of the familiarity with Taiwanese investment vehicles were significant, and 13 results of the familiarity with foreign investment vehicles were significant. The results in Table 4 demonstrate that the investor's home-bias investment increased with higher familiarity with Taiwanese investment vehicles (which were consistent with those of Gehrig [8], Brennan and Cao [9]; however, the investor's home-bias investment did not decrease with higher familiarity with the foreign investment vehicles. Moreover, the amount of Taiwanese time deposit $\mathrm{s}$ decreased with increased 
Citation: Huang WL, Fu YK (2014) Home-Bias Investment Measure: Evidence from a Repeated Experiment in Taiwan. J Bus Fin Aff 3:117 doi:10.4172/2167-0234.1000117

Page 6 of 9

\begin{tabular}{|c|c|c|c|c|}
\hline & investment portfolio & Types of Information & investment vehicles & Correlation coefficient \\
\hline \multirow{5}{*}{ age } & \multirow{2}{*}{ Type B } & no information & foreign mutual funds & $-0.156^{*}$ \\
\hline & & basic information & Taiwanese mutual funds & $0.175^{*}$ \\
\hline & \multirow{3}{*}{ Type C } & no information & Taiwanese ETF & $0.191^{*}$ \\
\hline & & no information & foreign mutual funds & $-0.207^{* *}$ \\
\hline & & basic information & foreign mutual funds & $-0.184^{*}$ \\
\hline \multirow{7}{*}{ annual income } & Type A & no information & Taiwanese ETF & $0.156^{*}$ \\
\hline & \multirow{2}{*}{ Type B } & basic information & Taiwanese mutual funds & $0.216^{* *}$ \\
\hline & & all information & Taiwanese mutual funds & $0.166^{*}$ \\
\hline & \multirow{4}{*}{ Type C } & no information & Taiwanese ETF & $0.245^{\star *}$ \\
\hline & & performance information & Taiwanese ETF & $0.208^{* *}$ \\
\hline & & basic information & Taiwanese ETF & $0.197^{*}$ \\
\hline & & basic information & foreign mutual funds & $-0.153^{*}$ \\
\hline number of investment courses & N/A & & & \\
\hline \multirow{3}{*}{ amount of annual investment } & Type B & basic information & foreign mutual funds & $-0.164^{*}$ \\
\hline & \multirow{2}{*}{ Type C } & \multirow{2}{*}{ no information } & Taiwanese ETF & $0.165^{*}$ \\
\hline & & & foreign mutual funds & $-0.160^{*}$ \\
\hline
\end{tabular}

Note: ${ }^{*} p<.05,{ }^{* *} p<.01$

Table 3: Correlation analyses of the subjects' personal variables and investment ratio.

\begin{tabular}{|c|c|c|c|c|}
\hline & Investment portfolio & Types of Information & Investment vehicles & Correlation coefficient \\
\hline \multirow{10}{*}{$\begin{array}{l}\text { familiarity with Taiwanese invest- } \\
\text { ment vehicles }\end{array}$} & \multirow{2}{*}{ Type A } & no information & Taiwanese time deposit & $-0.184^{*}$ \\
\hline & & basic information & Taiwanese time deposit & $-0.169^{*}$ \\
\hline & \multirow{4}{*}{ Type B } & no information & Taiwanese mutual funds & $0.193^{*}$ \\
\hline & & performance information & Taiwanese mutual funds & $0.186^{*}$ \\
\hline & & basic information & Taiwanese mutual funds & $0.221^{* *}$ \\
\hline & & all information & Taiwanese mutual funds & $0.158^{*}$ \\
\hline & \multirow{4}{*}{ Type C } & no information & Taiwanese ETF & $0.184^{*}$ \\
\hline & & performance information & Taiwanese ETF & $0.261^{* *}$ \\
\hline & & basic information & Taiwanese time deposit & $-0.158^{*}$ \\
\hline & & all information & Taiwanese ETF & $0.174^{*}$ \\
\hline \multirow{13}{*}{$\begin{array}{l}\text { familiarity with foreign invest- } \\
\text { ment vehicles }\end{array}$} & \multirow{5}{*}{ Type A } & no information & Taiwanese time deposit & $-0.216^{* *}$ \\
\hline & & performance information & Taiwanese time deposit & $-0.174^{*}$ \\
\hline & & \multirow{2}{*}{ basic information } & foreign ETFs & $0.178^{*}$ \\
\hline & & & Taiwanese time deposit & $-0.200^{*}$ \\
\hline & & all information & Taiwanese time deposit & $-0.154^{*}$ \\
\hline & \multirow{2}{*}{ Type B } & no information & Taiwanese time deposit & $-0.184^{*}$ \\
\hline & & basic information & Taiwanese time deposit & $-0.163^{*}$ \\
\hline & \multirow{6}{*}{ Type C } & no information & Taiwanese time deposit & $-0.179^{*}$ \\
\hline & & performance information & Taiwanese time deposit & $-0.184^{*}$ \\
\hline & & \multirow{2}{*}{ basic information } & foreign ETFs & $0.190^{*}$ \\
\hline & & & Taiwanese time deposit & $-0.189^{*}$ \\
\hline & & \multirow{2}{*}{ all information } & foreign ETFs & $0.178^{*}$ \\
\hline & & & Taiwanese time deposit & $-0.155^{*}$ \\
\hline
\end{tabular}

Note: ${ }^{*} p<.05,{ }^{* *} p<.01$

Table 4 Correlation analyses of the subjects' familiarity with Taiwanese (Foreign) investment vehicles and each investment ratio.

familiarity with foreign investment vehicles. The purpose of including the Taiwanese time deposit (a risk-free investment vehicle) in this study was for investors to control the risk of the investment portfolio; the amount of the Taiwanese time deposit decreased with increased familiarity with foreign investment vehicles. The results were similar to those of previous studies in that the investor's risk tolerance level increased with familiarity with investment vehicles. For Taiwanese ETFs and Taiwanese mutual funds, there was a significant positive correlation between the Taiwanese investor's investment ratio and familiarity with the Taiwanese investment vehicles. For the Taiwanese time deposit, there was a significant negative correlation between the Taiwanese investor's investment ratio and familiarity with the Taiwanese investment vehicles. For foreign ETFs, there was a significant positive correlation between the Taiwanese investor's investment ratio and familiarity with the foreign investment vehicles. For the Taiwanese time deposit, there was a significant negative correlation between the Taiwanese investor's investment ratio and familiarity with the foreign investment vehicles.

The analysis of variance of the ratio of investment between the subject $\mathrm{s}$ in Group 1, 2, 3 and 4 and those in the other 3 groupings is provided in Table 5. The framing effect of home-bias investment may exist; however, it had insignificant effects. The results of the normality test (Kolmo gorov-Smirnova and Shapiro-Wilk) verified that there was a normal distribution in the groupings of the portfolio, the type of information and investment vehicles for the subjects from Groups 1, 2, 
3 and 4 . This study used independent sample T tests to explore whether there was a difference in the home-bias investment of Taiwanese investors based on the amount of information initially received. The results in Table 5 indicate that only 16 of the $176 \mathrm{~T}$ tests with an equal mean had significant results, of which 4 significant results were from Group 1, 0 from Group 2, 6 from Group 3 and 6 from Group 4.7

The results of the paired sample $\mathrm{T}$ test on the investment ratios when the same subject received different types of information or portfolios are presented in Tables 6 and 7. The home-bias investment of Taiwanese investors varied with the level of information asymmetry; therefore, the Taiwanese government could reduce the level of information asymmetry of investment vehicles or the level of control, thereby reducing investor's home-bias investment. The results in Tables 6 and 7 indicate that the paired sample T tests exhibited partly significant differences in the investment ratios when the Taiwanese investor received different types of information; moreover, the paired sample $T$ test results were all significant when the same subject received different portfolios. In addition, the descriptive statistical results indicate that the investment ratio of Taiwanese investment vehicles decreased with an increase in the number of investment vehicles.

The results in Table 6 demonstrate that the reduction in the level of information asymmetry of investment vehicles could not improve the home-bias investment of Taiwanese investors in some investment vehicles (such as Taiwanese ETFs). Only the disclosure of a certain type of information (such as performance) could reduce the level of information asymmetry of investment vehicles. None of the results of the paired sample $\mathrm{T}$ tests were significant concerning the investment ratio of Taiwanese ETFs when the same Taiwanese investor received different types of information; moreover, the investment ratio of Taiwanese mutual funds when the same Taiwanese investor received the information of performance (or all of the information) was significantly different from that when the same Taiwanese investor received no information or basic information.

The result $s$ of the regression equation that used the investment ratio of Taiwanese ETFs and Taiwanese mutual funds as the dependent variable and investor's personal variables and domestic and foreign investment vehicles as independent variables are provided in Table
8. The investment ratio of Taiwanese ETFs and Taiwanese mutual funds decreased with an increase in the number of investment vehicles (Table 8, constant value). When the controlled level of information asymmetry was excluded, the investor's familiarity with the Taiwanese investment vehicles significantly positively affected the investment ratio of Taiwanese ETFs and Taiwanese mutual funds, which is consistent with the hypothesis of this study. That is, one reason for the home-bias investment is the investor's over-investment in Taiwanese investment vehicles because of familiarity with the Taiwanese investment vehicles, while familiarity with foreign investment vehicles had no definitive effect ${ }^{8}$.

The results in Table 8 indicate that when the controlled level of information asymmetry was excluded, the investor's educational level significantly positively affected the investment ratio of the Taiwanese mutual funds, and the investor's annual income significantly positively affected the investment ratio of the Taiwanese ETFs. When the results of Tables 2-4 and Table 8 are combined, it can be observed that the results are almost identical. Therefore, the effect of the subjects' personal variables on the investment ratios did not vary significantly based on the level of information asymmetry.

\section{Conclusions}

This study used experimental questionnaires to control the level of information asymmetry and explored the effect of an investor's level of information asymmetry and familiarity with domestic and foreign investment vehicles on home-bias investment. Based on the descriptive statistical results of the questionnaires and the analytical results of the regression equation, the reason for home-bias investment is the investor's over-investment into Taiwanese investment vehicles because of information asymmetry or familiarity. In addition, the level of home-bias investment of Taiwanese investors was lower than that in previous studies, which was due to the high level of internalization

${ }^{7}$ This study calculated the results of $176 \mathrm{~T}$ tests with an equal mean based on the four groups of subjects, the four types of information and eleven investment vehicles (three types of portfolio).

${ }^{8}$ This study compiled all the data (the level of information asymmetry was excluded) for the regression equation.

\begin{tabular}{|c|c|c|c|c|c|}
\hline & investment portfolio & Types of Information & Investment vehicles & Levene Test(F) & T test \\
\hline \multirow{4}{*}{ Group 1 VS. the other 3 groups } & Type A & performance information & Taiwanese ETF & 1.453 & $2.206^{*}$ \\
\hline & & & Taiwanese time deposit & 0.545 & $2.082^{*}$ \\
\hline & & basic information & Taiwanese time deposit & 0.041 & $-2.164^{*}$ \\
\hline & Type C & no information & Foreign ETFs & 0.519 & $-1.978^{*}$ \\
\hline Group 2 VS. the other 3 groups & \multicolumn{5}{|c|}{ None } \\
\hline \multirow{6}{*}{ Group 3 VS. the other 3 groups } & Type A & all information & Taiwanese ETF & 1.690 & $2.729^{* *}$ \\
\hline & Type B & no information & Foreign mutual funds & $6.576^{*}$ & $2.511^{*}$ \\
\hline & & & Taiwanese time deposit & $16.405^{\star \star \star}$ & $-2.528^{*}$ \\
\hline & & basic information & foreign mutual funds & 1.954 & $2.033^{*}$ \\
\hline & Type C & no information & foreign mutual funds & 1.359 & $2.258^{*}$ \\
\hline & & basic information & Taiwanese time deposit & $12.827^{* * *}$ & $-2.148^{*}$ \\
\hline \multirow{6}{*}{ Group 4 VS. the other 3 groups } & Type A & no information & Taiwanese ETF & 0.408 & $-1.973^{*}$ \\
\hline & & performance information & Taiwanese ETF & 2.303 & $-2.145^{*}$ \\
\hline & & all information & Taiwanese ETF & 1.034 & $-2.022^{*}$ \\
\hline & & & Taiwanese time deposit & 3.185 & $2.066^{*}$ \\
\hline & Type B & no information & foreign mutual funds & 2.716 & $-2.174^{*}$ \\
\hline & Type C & basic information & foreign ETFs & 1.442 & $-1.977^{*}$ \\
\hline
\end{tabular}

Note: ${ }^{*} p<.05,{ }^{* *} p<.01$

Table 5: The analysis of variance of the subjects' investment ratios between Groups 1, 2, 3 and 4 and the other 3 groups. 
Citation: Huang WL, Fu YK (2014) Home-Bias Investment Measure: Evidence from a Repeated Experiment in Taiwan. J Bus Fin Aff 3:117 doi:10.4172/2167-0234.1000117

Page 8 of 9

\begin{tabular}{|c|c|c|c|}
\hline Investment portfolio & Types of Information & Investment vehicles & T tests \\
\hline \multirow{2}{*}{ Type B } & no information VS. performance information & \multirow{2}{*}{ Taiwanese mutual funds } & $-3.345^{*}$ \\
\hline & no information VS. all information & & $-2.402^{*}$ \\
\hline \multirow{8}{*}{ Type C } & \multirow{2}{*}{ no information VS. performance information } & Taiwanese mutual funds & $-4.211^{* *}$ \\
\hline & & Foreign ETFs & $3.587^{* *}$ \\
\hline & \multirow{2}{*}{ no information VS. all information } & Taiwanese mutual funds & $-3.528^{*}$ \\
\hline & & foreign mutual funds & $-2.215^{*}$ \\
\hline & \multirow{2}{*}{ performance information VS. basic information } & Taiwanese mutual funds & $3.256^{*}$ \\
\hline & & Foreign ETFs & $-3.163^{*}$ \\
\hline & performance information VS. all information & Foreign ETFs & $-2.167^{*}$ \\
\hline & basic information VS. all information & Taiwanese mutual funds & $-2.455^{*}$ \\
\hline
\end{tabular}

Note: ${ }^{*} \mathrm{p}<.05,{ }^{* *} \mathrm{p}<.01$

Table 6: Paired sample T test of the same subject's investment ratio when presented with different types of information.

\begin{tabular}{|c|c|c|c|}
\hline investment portfolio & Types of Information & investment vehicles & $\mathrm{T}$ tests \\
\hline \multirow{8}{*}{ Type A VS. Type C } & \multirow{2}{*}{ no information } & Taiwanese ETF & $14.544^{* *}$ \\
\hline & & foreign ETFs & $17.227^{\star \star}$ \\
\hline & \multirow{2}{*}{ Performance information } & Taiwanese ETF & $13.613^{* *}$ \\
\hline & & foreign ETFs & $16.739^{* *}$ \\
\hline & \multirow{2}{*}{ basic information } & Taiwanese ETF & $14.682^{* *}$ \\
\hline & & foreign ETFs & $14.922^{* *}$ \\
\hline & \multirow{2}{*}{ all information } & Taiwanese ETF & $14.656^{* *}$ \\
\hline & & foreign ETFs & $15.107^{* *}$ \\
\hline \multirow{8}{*}{ Type B VS. Type C } & \multirow{2}{*}{ no information } & Taiwanese mutual funds & $8.729^{* *}$ \\
\hline & & foreign mutual funds & $12.661^{* *}$ \\
\hline & \multirow{2}{*}{ Performance information } & Taiwanese mutual funds & $7.269^{\star *}$ \\
\hline & & foreign mutual funds & $13.108^{* *}$ \\
\hline & \multirow{2}{*}{ basic information } & Taiwanese mutual funds & $9.621^{* *}$ \\
\hline & & foreign mutual funds & $14.009^{* *}$ \\
\hline & \multirow{2}{*}{ all information } & Taiwanese mutual funds & $7.773^{* *}$ \\
\hline & & foreign mutual funds & $10.877^{* *}$ \\
\hline
\end{tabular}

Note: ${ }^{*} p<.05,{ }^{* *} p<.01$

Table 7: Paired sample T test of the same subject's investment ratio when presented with different portfolios.

\begin{tabular}{|c|c|c|c|c|}
\hline & $\begin{array}{l}\text { investment portfolio of type A's } \\
\text { Taiwanese ETF }\end{array}$ & $\begin{array}{l}\text { investment portfolio of type B's } \\
\text { Taiwanese mutual funds }\end{array}$ & $\begin{array}{l}\text { investment portfolio of type C's } \\
\text { Taiwanese ETF }\end{array}$ & $\begin{array}{l}\text { investment portfolio of type C's } \\
\text { Taiwanese mutual funds }\end{array}$ \\
\hline constant & $0.290^{* * *}$ & $0.131^{* * *}$ & $0.083^{* *}$ & $0.061^{*}$ \\
\hline gender & -0.009 & -0.008 & $0.024^{*}$ & -0.014 \\
\hline age & 0.000 & $-7.923 \times 10-5$ & 0.000 & $9.737 \times 10-5$ \\
\hline education level & -0.007 & $0.055^{\star *}$ & 0.018 & $0.054^{* * *}$ \\
\hline occupation & $-0.053^{* *}$ & 0.012 & 0.005 & 0.004 \\
\hline annual income & $1.137 \times 10-7^{*}$ & $6.885 \times 10-8$ & $1.178 \times 10-7^{* \star *}$ & $-2.743 \times 10-9$ \\
\hline number of investment courses & 0.000 & 0.000 & -0.001 & 0.000 \\
\hline annual investment & -7 & -8 & -8 & -7 \\
\hline investment experience & $0.001^{*}$ & -0.013 & -0.014 & $0.029^{*}$ \\
\hline $\begin{array}{l}\text { Domestic investment } \\
\text { tool familiarity }\end{array}$ & $0.010^{* *}$ & $0.016^{* * *}$ & $0.014^{* * *}$ & $0.008^{* *}$ \\
\hline $\begin{array}{l}\text { Foreign investment } \\
\text { tool familiarity }\end{array}$ & -0.006 & $-0.014^{\star *}$ & $-0.011^{*}$ & -0.008 \\
\hline
\end{tabular}

Note: ${ }^{*} p<.05,{ }^{* *} p<.01$

Table 8: The effect of the investor's personal variables and level of familiarity with domestic and foreign investment vehicles on their home-bias investment (regression coefficient).

of the Taiwanese financial market and the universality of financial knowledge among the Taiwanese population, as well as the fact that the subject s' behavior was simulated rather than actual. Therefore, this stud y suggests that future researchers can re-explore this topic using long-term real investigative data.

This stud $y$ used repetitive experimental questionnaires, independent sample $\mathrm{T}$ tests and paired sample $\mathrm{T}$ tests to explore the effect of the framing effect and the level of information asymmetry on home-bias investment. The results demonstrate that the effect of the framing effect on home-bias investment may exist but is small. In addition, the home-bias investment of Taiwanese investors varied with the level of information asymmetry, and only the disclosure of certain types of information (such as performance) or an increase in the number of investment vehicles could change the level of information asymmetry. Therefore, the Taiwanese government could reduce the 
Citation: Huang WL, Fu YK (2014) Home-Bias Investment Measure: Evidence from a Repeated Experiment in Taiwan. J Bus Fin Aff 3:117 doi:10.4172/2167-0234.1000117

Page 9 of 9

level of information asymmetry of investment vehicles (disclosure of the performance of investment vehicles) or the level of control (increase of number of investment vehicles), thereby reducing the level of investor home-bias investment.

This study used independent sample $\mathrm{T}$ tests, correlation analysis and regression equations to explore the effect of the investor's personal variables and familiarity with domestic and foreign investment vehicles on the home-bias investment. The majority of the investment ratios of Taiwanese investors did not vary significantly based on gender, educational level, occupation, annual income, the number of investment courses previously taken, annual investment amount or investment experience. However, the investment ratio of Taiwanese investment vehicles varied significantly based on educational level, investment experience, age, annual income and annual investment amount. Moreover, the difference in the investment ratios did not vary with the level of information asymmetry.

The level of the home-bias investment of Taiwanese investors increased with an increase in familiarity with Taiwanese investment vehicles but did not decrease with an increase in familiarity with foreign investment vehicles. In addition, the amount of Taiwanese time deposit decreased with an increase in familiarity with Taiwanese and foreign investment vehicles. The results were similar to previous studies in that the investor's risk tolerance level increased as the level of familiarity with investment vehicles increased.

The results of this study demonstrate that the framing effect existed; however, its effect was small, which may be due to the one-hour rest time between experiments. It is suggested that future researchers can adjust the rest time to explore the effect of different experimental rest times on the framing effect.

\section{Reference}

1. Karolyi GA, Stulz RM (2002) Are Financial Assets Priced Locally or Globally? Handbook of Economics and Finance 1: 975-1020.

2. Howell M and Cozzini A (1990) London: alomon Brothers European Equity Research. International Equity Flows.

3. Cooper I, Kaplanis E (1994) Home Bias in Equity Portfolios, Inflation Hedging and International Capital Market Equilibrium. Review of Financial Studies 7: 45-60
4. Kang JK, R. Stulz RM (1996) Why is There a Home Bias? An Analysis of Foreign Portfolio Equity Ownership on Japan. Journal of Financial Economics 46: 3-28.

5. Tesar LL, Werner IM (2001) Home Bias and High Turnover. J Int Money Financ 14: 467-492.

6. Chan k, Vicentiu MC, and Lilian KN (2006) What Determines the Domestic Bias and Foreign Bias? Evidence form Mutual Fund Equity Allocations Worldwide. Journal of Finance 60: 1495-1534.

7. French KR, Poterba JM (1991) Investor Diversification and International Equity Markets. American Economic Review 81: 222-226.

8. Gehrig TP (1993) An Information Based Explanation of the Domestic Bias in International Equity Investment. Scand. J. of Economics 95: 97-109.

9. Brennan MJ and Cao HH (1997) International Portfolio Investment Flows Journal of Finance 52: 1851-1880.

10. Shiller RJ, Kon-Ya F, Tsutsui Y (1996) Why Did the NIKKEI Crash? Expanding the Scope of Expectations Data Collection. Review of Economics and Statistics 78: 156- 164.

11. Kilka M, Weber M (2000) Home Bias in International Stock Return Expectations. Journal of Psychology and Financial Markets 1: 176-192.

12. Ackert LF, Church BK, Tompkins J, Zhang $P$ (2003) What's in a Name? An Experimental Examination of Investor Behavior. Review of Finance 9: 281-304.

13. Strong N, Xu X (2003) Understanding the Home Equity Bias: Evidence from Survey Data. Review of Economics and Statistics 85: 307-312.

14. Huberman G (2001) Familiarity Breeds Investment. Review of Financial Studies 14: 659-680

15. Earl AA, Morgan B Jr (1976) Engineering Psychology and Human Performance. Annual Review of Psychology 27: 305-331.

16. Tversky A, Kahneman D (1981) The Framing of Decisions and the Psychology of Choice. Science 21: 453-458

17. Levin IP, Schneider SL, Gaeth GJ (1998) All Frames Are Not Created Equal: A Typology and Critical Analysis of Framing Effects. Organizational Behavior and Human Decision Processes 76:149-188.

18. Levin IP, Gaeth GJ (1988) How Consumers are Affected by the Framing of Attribute Information Before and After Consuming the Product. Journal of Consumer Research 15: 374-378.

19. Meyerowitz BE, Chaiken S (1987) The Effect of Message Framing on Breast Self-Examination Attitudes. J Pers Soc Psychol 52: 500-510. 